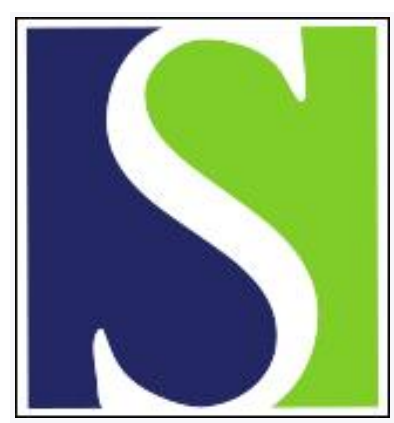

Scand J Work Environ Health 1986;12(5):455-460

https://doi.org/10.5271/sjweh.2112

Issue date: Oct 1986

Mortality experience in a polyamide-polyester factory.

by Hours M, Bertholon J, Esteve J, Cardis E, Freyssinet CL, Quelin P, Fabry J

This article in PubMed: www.ncbi.nlm.nih.gov/pubmed/3787217

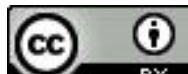




\title{
Mortality experience in a polyamide-polyester factory
}

\author{
by Martine Hours, MD, ${ }^{1}$, Jacques Bertholon, MD, ${ }^{2}$ Jacques Esteve, $\mathrm{PhD},{ }^{3}$ Elisabeth Cardis, $\mathrm{PhD},{ }^{3}$ \\ Claire Lise Freyssinet, MD, ${ }^{2}$ Pierre Quelin, MD, ${ }^{2}$ Jacques Fabry, MD'
}

\begin{abstract}
HOURS M, BERTHOLON J, ESTEVE J, CARDIS E, FREYSSINET CL, QUELIN P, FABRY J. Mortality experience in a polyamide-polyester factory. Scand $J$ Work Environ Health 12 (1986) $455-460$. Chemical workers have become increasingly concerned about the presence of carcinogens in their occupational environment. As a result, a number of studies of excess cancer mortality have been undertaken in groups of workers with well-characterized exposures. This paper reports the results of one such study carried out in a polyamide-polyester factory in France. A retrospective cohort design was chosen to evaluate the effect of exposure to phthalates, nickel catalyzers, and other chemicals in the work environment. Only a slight excess of cancers, marginally related to exposure category yet not significantly related to length of exposure, was found. The cohort, however, was young but stable, and a continued follow-up is therefore both feasible and justifiable, since it is likely to yield important information about the potential hazards associated with the tergal polymer industry.
\end{abstract}

Key terms: cohort study, mortality statistics, occupational exposure.

In 1981-1982 a mortality study was undertaken in a chemical factory near Lyon, France. Its aim was to investigate a potential excess of deaths from cancers of various sites among the employees of the factory.

The study was motivated by concern, expressed to the medical service of the factory by the staff representatives, about an apparently high number of malignant tumors among the personnel. Because of the widespread use of nickel $(4,6,14)$ as a catalyzer in the factory and because of suspicions about the possible carcinogenic effect of phthalates (8), also present in the factory, a preliminary analysis was undertaken comparing the distribution of cancer deaths, as available from the medical service, to that in the general population. The results of a proportional mortality analysis confirmed the potential existence of an excess risk, particularly for cancers of the pharynx, pancreas, and lung. This approach has well known limitations; a full retrospective cohort study was therefore undertaken in order to evaluate the excess more precisely. The cohort study was carried out jointly by the Medical Service of the Rhône-Poulenc Society and the Institute of Social Medicine of the Claude-Bernard University in Lyon.

This article presents the results from the first analysis of mortality in the cohort, followed to the end of 1981.

1 Institut de Médecine sociale, Université LYON I (Member of the »Groupement scientifique GS025 CNRS - HCL), Hôpital Lyon-Sud, F-69310 Pierre Bénite, France.

2 Rhône Poulenc, Chimie de Base, Belle Etoile, F-69190 SaintFons, France.

3 International Agency for Research on Cancer, Unit of Biostatistics and Field Studies, 150 cours Albert-Thomas, F-69372 Lyon Cédex 08, France.

Reprint requests to: Dr M Hours, Institut de Médecine sociale, Université Lyon I, Hôpital Lyon-Sud, Bât 1G, F-69310 Pierre Bénite, France.

\section{Description of the factory}

The Belle-Etoile plant is located in the southern suburbs of Lyon. It is part of the Rhône-Poulenc group, a leading French chemical company. The plant employs an average of 1900 workers. There is roundthe-clock production with $50 \%$ of the personnel working the day shift. The activities are divided into production, maintenance, and analysis and control.

The plant was built in 1950. It became fully operational in 1962. A total of 3837 workers has been employed since then ( 3679 men and 158 women). The production is highly specialized comprising polyamide (51 $000 \mathrm{t} /$ year) and polyester (55000 t/year) for the textile industry and plastic substances. It is suspected that numerous potentially hazardous substances (ammonia, adipic acid, hexamethylene diamine, titanium oxide, Raney nickel, manganese and cobalt salts, terephthalic acid, paraxylene and ethylene glycol) have at one time been present in the occupational environment.

Environmental protection measures have recently been carried out. There has been considerable automation of the manufacturing processes since 1965 . The safety of some processes has, among other things, been improved by the setting up of control rooms outside the production areas.

The workforce of this plant is very stable in that $59.3 \%$ of the employees has worked only in one production area and $26 \%$ only in two.

\section{Methods}

The physician in charge of the medical service directly supervised the collection of job information (dates, production area, hours worked) and the ascertainment 


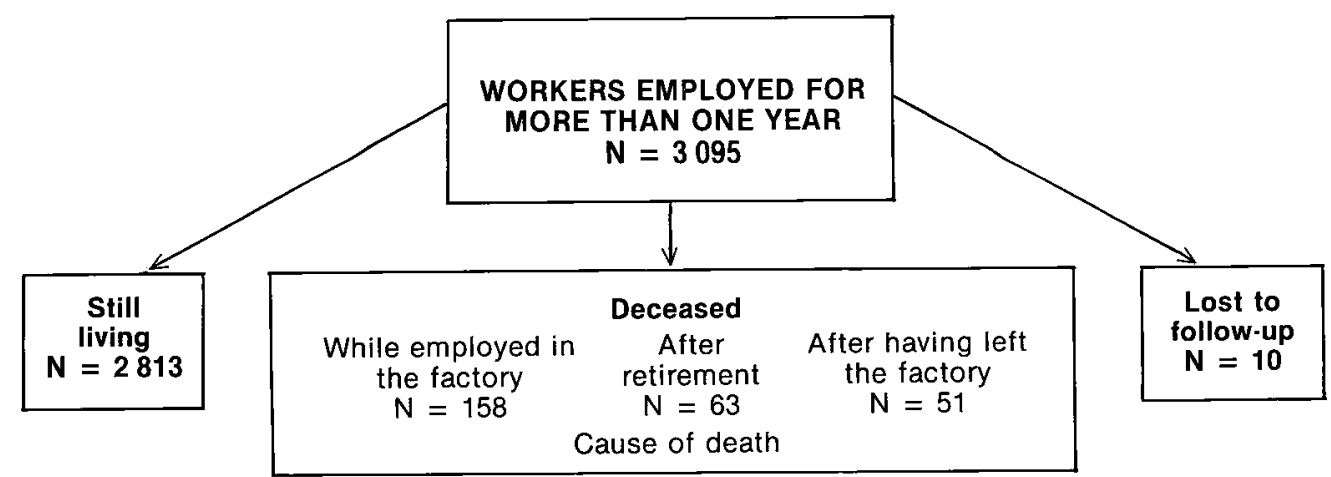

Figure 1. Summary of the follow-up.

of vital status. The information was obtained from factory records, as well as, for vital status, from records of the employee pension fund or, when necessary, municipal records at the birthplace.

The cohort included 3095 men employed for more than one year in at least one area of the plant. Figure 1 is a summary of their follow-up. Women $(\mathrm{N}=158)$ were excluded from the cohort because of their insufficient number. Also excluded were 586 men who were not employed more than one year in any area of the plant in an attempt to avoid a potential selection bias and because the little amount of information that might be gained through their inclusion did not justify the cost of obtaining it. (The majority of those excluded were transferred within the Rhône-Poulenc group during its reorganization in 1981.)

In France, researchers are not allowed access to death certificates. For this study, therefore, cause of death had to be obtained elsewhere, ie, from the personnel files of the medical service in the factory, from pension $(81.2 \%$ of the known causes of death obtained) or hospital records, or from the treating physicians $(10.8 \%)$ or next of kin $(8 \%)$. The causes thus identified were then coded following the rules and nosology of the ninth revision of the International Classification of Diseases (ICD) $(17,18,19,20)$.

The statistical analysis involved comparing mortality observed in the cohort with that, age- and calendaryear-standardized, expected in the French male population. Mortality rates for French men were obtained from the data banks of the World Health Organization and the French National Institute of Health and Medical Research (INSERM). Computations of person-years of follow-up and expected number of deaths were carried out using the classical modified lifetable analysis approach (5).

The standardized mortality ratio (SMR) was used as a measure of deviation between the observed and expected number of deaths. The significance, and a $95 \%$ confidence interval $(95 \% \mathrm{CI})$ for that estimate, were derived based on the assumption of a Poisson distribution of the number of deaths.

For a more refined analysis, in lieu of actual exposure categories, employees were classified as working in one of the following: (i) administration, (ii) nylon manufacture, (iii) tergal manufacture, or (iv) maintenance and central laboratory.

A fifth category, "mobile workers," was also created and defined as those employees who worked in more than one of the other four categories. For analysis purposes, workers entered this category only when they started their second job. In this process first jobs with less than one year's duration were ignored. Note that most of the "mobile workers" were employees promoted from production to maintenance or to the central laboratory.

The distinctions between categories 1 through 4 were established because the workers in these areas had rather different exposures. The administration workers represent, most likely, an unexposed population; therefore a worker who worked both in administration and in, say, nylon production, was classified as a nylon worker rather than as a mobile worker, at least until the beginning of his next job.

The nylon workers were either employed in the production of nylon salt, which began in 1952, or in that of the polymer nylon 6-6, which began in 1958. They were also exposed to Raney nickel (9), used as a catalyzer.

The tergal workers were employed in the production or polymerization of dimethylterephthalate, which began in 1956. The carcinogenicity of this chemical has never been tested, although some related compounds are thought to be carcinogenic $(10,11)$.

The fourth subcohort comprised skilled workers employed in all sections of the plant for the maintenance of various machines, as well as employees in the central laboratories. Both of these groups may have been exposed to all the aforementioned chemicals.

The SMR values for different causes of death were calculated for the five employment categories as a descriptive analysis of the differential risks between categories. The very small number of deaths observed for all sites of cancer, except lung, did not warrant more refined analyses. The statistical analysis was performed on data from the 3087 individuals who spent at least one year in one of the exposure categories and whose exposure history was complete. 
Length of employment in the five exposure categories was compared for the 26 lung cancer cases observed and up to 30 referents chosen at random from the members of the cohort born in the same period ( \pm 2 years) and alive at the time of death of the case. A test for association between lung cancer risk and duration of exposure was performed using the conditional logistic regression (3).

\section{Results}

The main characteristics of the 3095 employees in the cohort are presented in table 1 . Most of the employees were French. They formed a stable workforce, with an average of 14.6 work years in the factory. Eighty-three percent of the employees was hired between 1950 and 1964. Fewer than half of the individuals in the cohort were over 30 years old at the time of hiring. Therefore $90.6 \%$ of the cohort was still alive at the end of the study period. Of the remainder, $9 \%$ was dead, and only $0.4 \%$ was lost to follow-up. The circumstances of death were known for all but $8.5 \%$ of the dead subjects.

The age and calendar-period distribution of personyears of observation, a total of 56817 , is shown in table 2. It should be noted that $90 \%$ of the personyears were accumulated in the age range of 15 to 54 years.

Mortality by specific cause is given in table 3 . Total mortality was lower in the cohort than in the reference population (SMR 80), primarily due to a deficit of deaths in the following categories: accidents and violent deaths, cardiovascular disease, diseases of the nervous system, nonmalignant respiratory diseases and infectious diseases, endocrine and metabolic diseases, and diseases of the digestive tract. Of the last category, it should be noted that deaths from cirrhosis of the liver were observed at their expected level.

The number of deaths from cancer (all sites), however, was slightly higher than expected. Based on a one-sided test, the observed excess was significant at the 0.05 level. As can be seen in table 3, excesses were observed for the following sites: esophagus, intestine, rectum, larynx, lung, skin, prostate, and other malignant neoplasms. The excess was statistically significant at the 0.05 level only for skin (ICD-9 $172-173$ ) with three cases and an SMR of 368.7 and for lung (ICD-9 162) with 26 cases and an SMR of 148.6. The lung cancer excess was further analyzed by exposure category.

The observed and expected numbers of deaths from various causes are presented in table 4 by exposure category. Factory workers tend to be healthier than the general population; the SMR values for all causes of death were therefore not unexpectedly low. The SMR of the fifth group, that of mobile workers, was the lowest.

Cancer mortality was in excess for nylon and tergal workers. The excess was statistically significant. Significant excesses were observed for skin, larynx, lung cancer, and other malignant neoplasms. For other malignant neoplasms the excess was restricted to nylon workers. For skin cancer, the excess was observed for both tergal (one squamous cell epithelioma) and nylon (two melanomas) workers. There were only three cases, however, and conclusions about exposures associated with this disease would be premature.

Table 5 shows the distribution of deaths from cancers of sites that have been investigated in studies of the chemical industry $(1,13,15,16)$, but for which an SMR analysis was not performed because of the coding of general mortality data following the sixth and seventh revisions of the ICD for the years 1950$1968(17,18)$. For cancer of the larynx the excess was observed for tergal and maintenance workers. It was statistically significant for the tergal workers. For cancer of the lung the excess was observed for tergal, maintenance, and mobile workers. It was statistically significant for the maintenance workers. It is interest-

Table 1. Characteristics of the study population.

\begin{tabular}{lrr}
\hline Characteristic & Number & $\%$ \\
\hline Nationality & & \\
French & 3040 & 98.0 \\
Other & 55 & 2.0 \\
Age at hire (years) & & \\
$\leq 29$ & 1564 & 50.5 \\
$30-39$ & 969 & 31.3 \\
$>39$ & 562 & 18.2 \\
Date of hire & & \\
$1950-1954$ & 401 & 13.0 \\
$1955-1959$ & 798 & 25.8 \\
$1960-1964$ & 1317 & 42.5 \\
After 1964 & 579 & 18.7 \\
\hline
\end{tabular}

Table 2. Distribution of the 56806 person-years of observation.

\begin{tabular}{lccccrrr}
\hline $\begin{array}{l}\text { Age } \\
\text { group } \\
\text { (years) }\end{array}$ & $1950-1954$ & $1955-1959$ & $1960-1964$ & $1965-1969$ & $1970-1974$ & $1975-1981$ & Total \\
\cline { 2 - 7 }$y$ & 224 & 1740 & 4491 & 5159 & 2856 & 1320 & 15790 \\
$15-34$ & 137 & 1047 & 3556 & 6946 & 9507 & 14038 & 35231 \\
$35-54$ & 17 & 69 & 167 & 545 & 1201 & 3723 & 5722 \\
$55-74$ & - & - & - & 1 & 14 & 48 & 63 \\
$\geq 75$ & 378 & 2856 & 8214 & 12651 & 13578 & 19129 & 56806 \\
\hline Total & & & & & & &
\end{tabular}


Table 3. Mortality among workers of the "Belle Etoile" factory by specific cause for 1950 to 1981 . (SMR = standardized mortality ratio)

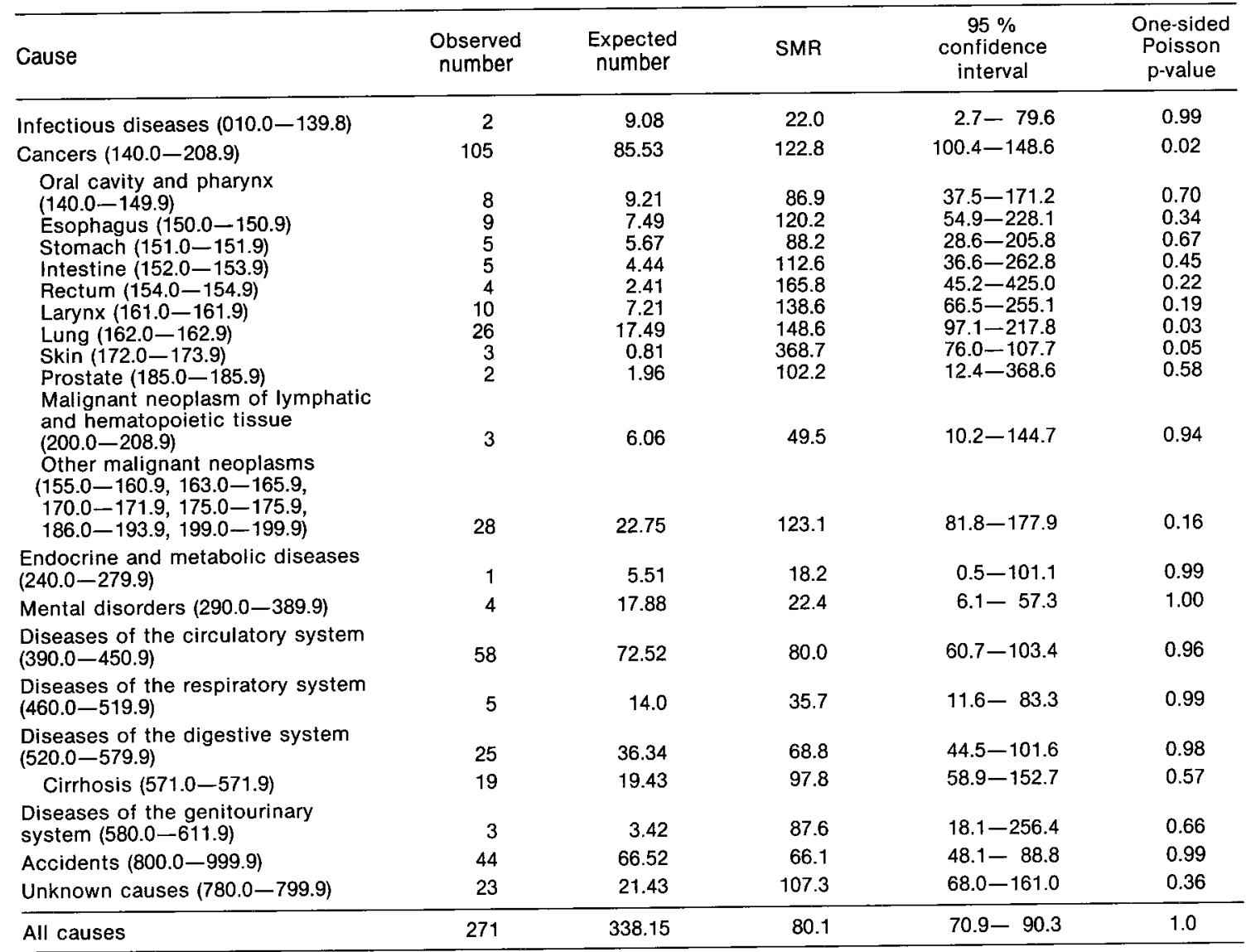

a Code of the International Classification of Diseases, ninth revision, in parentheses.

ing to note that all three categories, tergal, maintenance and mobile, might well have had similar, if not all well characterized, exposures. All four persons with lung cancer in the mobile worker group worked in tergal production. One could therefore define a "tergal work environment" category regrouping tergal, mobile, and maintenance workers.

In this "tergal work environment" category 15 lung and 6 laryngeal cancers were observed where only 8.2 and 3.5, respectively, were expected. The SMR then becomes $182.9(95 \% \mathrm{CI} 102.4-301.7)$ for lung cancer and 171 (95\% CI 62.9-373.1) for larynx.

A comparison of the exposure characteristics of the cases and the referents (described in the Methods section), in order to assess a potential excess risk of lung cancer associated with the tergal work environment, revealed that cases were employed an average of 1.11 years longer than the referents in the tergal production unit. However, eight cases were exposed longer in this unit than their corresponding referents, 14 were less exposed, and for four neither the case nor the referent was exposed. A test of trend for the association between lung cancer risk and duration of employ- ment in the tergal production unit was not significant (standardized slope $=1.03, \mathrm{p}=0.30$ ).

In an attempt to assess the possible existence of a risk which could have been present in the past and disappeared with the evolution of technology and the introduction of new processes, mortality by hiring period was considered. The excess of lung cancers seems confined to the individuals hired in 1950-1954 when the factory was set up ( 9 observed versus 4.5 expected) and in 1960-1965 when a large number of individuals was hired because of a major increase in tergal production (11 observed versus 6.1 expected). Neither excess, however, was significant. The excess of cancers of all sites was also slightly higher for employees hired between 1960 and 1965 (46 observed versus 29.9 expected). It should be noted, however, that no association of risk with time since beginning of exposure was found.

\section{Discussion}

The employees of the "Belle-Etoile" chemical plant constitute a stable workforce. The quality of the 
factory's records of employment and death is good. Biases in the follow-up are therefore unlikely.

A potential source of bias is due to cause of death ascertainment. In France, death certificates are used to compile published mortality statistics but are not available to researchers. For the study, cause of death was therefore obtained from the physician some time after the death occurred, and it is possible that it differs from that written on the death certificate. The authors believe, however, that this bias is negligible.

As for the workers who were lost to follow-up, it should be noted that they were few and that untraceability is generally due to an error in the civil status, as available in the factory records, which prevents identification in the municipality of birth.

The number of deaths for which cause is unknown was acceptable and comparable to that in the general population (SMR 106). This result tends to confirm the quality of the mortality data collected.

The usual peculiarities of industrial cohort studies, in particular the healthy worker effect (12), can be seen operating in this cohort in that mortality was lower than in the reference population. This occurrence is usually due to a selective hiring of healthy employees in industrial environments. The effect was particularly visible among the mobile and maintenance workers and might be explained by the strict selection, both at hiring and during employment, which these workers underwent $(2,7)$.

The fact that cancer mortality was close, if not slightly higher, to that of the general population confirms the hypothesis that the mortality deficit observed in this cohort was a healthy worker effect. Logically, such an effect is not expected for cancer mortality.

For most sites of cancer, the number of deaths was very small. The risk of lung and skin cancer, however, appeared to be slightly elevated. Since there were only three deaths from skin cancer, any conclusion is premature.

Both the nylon and tergal workers had a statistically significant elevated risk of cancer. Tergal workers seemed to be at high risk of cancer of the lung and larynx, whereas nylon workers were at high risk of cancer of the skin (two cases) and "other" malignant neoplasms (brain, pancreas, bladder, urinary tract, liver, and gall bladder). An interesting result of this analysis is that maintenance and perhaps mobile workers were also at an elevated risk for lung and laryngeal cancer. An appealing explanation of this phenomenon is that of a common tergal exposure.
The small number of cases of laryngeal cancer does not warrant any further analyses. For lung cancer, an analysis by length of employment did not confirm a causal effect of tergal exposure. In addition the number of lung cancer cases was small, and the exposures were only crudely described by the job categorization. Nevertheless a causal effect cannot be dismissed.

The lack of specificity of the exposure category definition also precludes any conclusions about tobacco. Intuitively, the observed risk could be due to smoking, since it is well known that factory workers tend to smoke more than the general population. However, it is difficult a priori to explain the observed differences in risk between nylon and tergal produc-

Table 4. Mortality from selected causes of death according to exposure category. $(O=$ observed number, $E=$ expected number, SMR = standardized mortality ratio)

\begin{tabular}{|c|c|c|c|c|}
\hline Cause of death & 0 & $E$ & \multicolumn{2}{|c|}{ SMR $^{a}$} \\
\hline \multicolumn{5}{|l|}{ All tumors } \\
\hline $\begin{array}{l}\text { Nylon workers } \\
\text { Tergal workers } \\
\text { Maintenance workers } \\
\text { Mobile workers } \\
\text { Unexposed workers }\end{array}$ & $\begin{array}{r}44 \\
24 \\
7 \\
14 \\
16\end{array}$ & $\begin{array}{r}30.34 \\
16.25 \\
8.18 \\
15.54 \\
30.34\end{array}$ & $\begin{array}{r}145.0 \\
147.7 \\
85.6 \\
90.1 \\
105.2\end{array}$ & $\begin{array}{l}(0.01) \\
(0.04)\end{array}$ \\
\hline \multicolumn{5}{|l|}{ Lung cancer } \\
\hline $\begin{array}{l}\text { Nylon workers } \\
\text { Tergal workers } \\
\text { Maintenance workers } \\
\text { Mobile workers } \\
\text { Unexposed workers }\end{array}$ & $\begin{array}{l}7 \\
6 \\
5 \\
4 \\
4\end{array}$ & $\begin{array}{l}6.17 \\
3.29 \\
1.65 \\
3.28 \\
3.09\end{array}$ & $\begin{array}{l}113.4 \\
182.4 \\
303.3 \\
121.9 \\
129.2\end{array}$ & $(0.03)$ \\
\hline \multicolumn{5}{|l|}{ Larynx cancer } \\
\hline $\begin{array}{l}\text { Nylon workers } \\
\text { Tergal workers } \\
\text { Maintenance workers } \\
\text { Mobile workers } \\
\text { Unexposed workers }\end{array}$ & $\begin{array}{l}3 \\
4 \\
1 \\
1 \\
1\end{array}$ & $\begin{array}{l}2.59 \\
1.40 \\
0.68 \\
1.38 \\
1.16\end{array}$ & $\begin{array}{r}116.0 \\
285.4 \\
147.0 \\
72.5 \\
86.0\end{array}$ & $(0.05)$ \\
\hline \multicolumn{5}{|c|}{ Other malignant neoplasms ${ }^{b}$} \\
\hline $\begin{array}{l}\text { Nylon workers } \\
\text { Tergal workers } \\
\text { Maintenance workers } \\
\text { Mobile workers } \\
\text { Unexposed workers }\end{array}$ & $\begin{array}{r}15 \\
4 \\
-4 \\
5\end{array}$ & $\begin{array}{l}8.10 \\
4.36 \\
2.18 \\
4.07 \\
4.02\end{array}$ & $\begin{array}{c}185.1 \\
91.7 \\
0 \\
98.1 \\
124.5\end{array}$ & $(0.02)$ \\
\hline \multicolumn{5}{|l|}{ Skin cancer } \\
\hline $\begin{array}{l}\text { Nylon workers } \\
\text { Tergal workers } \\
\text { Maintenance workers } \\
\text { Mobile workers } \\
\text { Unexposed workers }\end{array}$ & $\begin{array}{r}2 \\
1 \\
- \\
-\end{array}$ & $\begin{array}{l}0.29 \\
0.16 \\
0.08 \\
0.15 \\
0.13\end{array}$ & $\begin{array}{c}680.1 \\
611.6 \\
0 \\
0 \\
0\end{array}$ & $\begin{array}{l}(0.04) \\
(0.15)\end{array}$ \\
\hline \multicolumn{5}{|l|}{ All causes } \\
\hline $\begin{array}{l}\text { Nylon workers } \\
\text { Tergal workers } \\
\text { Maintenance workers } \\
\text { Mobile workers } \\
\text { Unexposed workers }\end{array}$ & $\begin{array}{r}104 \\
53 \\
25 \\
36 \\
53\end{array}$ & $\begin{array}{r}122.63 \\
66.72 \\
33.15 \\
57.06 \\
58.53\end{array}$ & $\begin{array}{l}84.8 \\
79.4 \\
75.4 \\
63.1 \\
90.6\end{array}$ & \\
\hline
\end{tabular}

a One-sided p-value in parentheses.

b See table 3 for a definition according to the code of the International Classification of Diseases, ninth revision.

Table 5. Distribution of other cancer sites of interest by exposure group.

\begin{tabular}{|c|c|c|c|c|c|}
\hline Exposure group & $\begin{array}{l}\text { Brain } \\
\text { cancer }\end{array}$ & $\begin{array}{l}\text { Bladder } \\
\text { cancer }\end{array}$ & $\begin{array}{l}\text { Urinary } \\
\text { tract cancer }\end{array}$ & $\begin{array}{l}\text { Liver, gall- } \\
\text { bladder cancer }\end{array}$ & $\begin{array}{c}\text { Pancreatic } \\
\text { cancer }\end{array}$ \\
\hline Nylon workers & 2 & 2 & 1 & 2 & 3 \\
\hline Tergal workers & $\overline{1}$ & - & - & - & - \\
\hline Maintenance workers & - & - & - & - & - \\
\hline Mobile workers & - & - & 1 & 1 & - \\
\hline Unexposed workers & - & - & 1 & - & 2 \\
\hline
\end{tabular}


tion workers by a difference in smoking habits. Once again, the number of cases was small and any conclusion potentially misleading. Incidentally, the SMR for lung cancer in the Rhône administrative region of France, where the plant is located, is 112 .

In conclusion, this study reveals a slightly increased risk of cancer in the nylon and tergal industry. The power of the study to detect any increase was small because of the relatively young age of the cohort. But the workforce is stable, and the exposures are presumably restricted to two well-identified groups of compounds. A continued follow-up of this cohort of chemical workers is therefore advisable, especially in order to gain more insight into the potential risk associated with the tergal work environment.

\section{Acknowledgments}

This study was supported by INSERM, contract no 828002 . The authors would gratefully like to acknowledge the help provided at various stages of the study by the following persons: Ms A Galfre, Ms C Nano, Ms A Rivoire, Mr M Jaboulin, Ms P Malindine, Dr L Simonato, and the medical staff of Rhône-Poulenc.

\section{References}

1. Austin SG, Schnotter AR. A cohort mortality study of petrochemical workers. J Occup Med 25 (1983) $304-312$.

2. Breslow NE. Cohort analysis in epidemiology. In: Atkinson AC, Fienberg SE, ed. A celebration of statistics. Springer Verlag, New York, NY 1985, pp 109-143.

3. Breslow NE, Day NE. Statistical methods in cancer research. Volume 1 (The analysis of case-control studies). International Agency for Research on Cancer, Lyon 1980. (IARC scientific publications no 32).

4. Chovil A, Sutherland RB, Holliday M. Respiratory cancer in a cohort of nickel sinter plant workers. $\mathrm{Br} \mathrm{J}$ Ind Med 38 (1981) 327-333.

5. Coleman M, Douglas A, Hermon C, Peto J. Cohort study analysis with a Fortran computer program. Int $\mathrm{J}$ Epidemiol (in press).

6. Doll R, Morgon LG, Speizer FE. Cancers of the lung and nasal sinuses in nickel workers. Br J Cancer 24 (1970) $623-632$.
7. Fox AJ, Collier PF. Low mortality rates in industrial cohort studies due to selection for work and survival in the industry. Br J Prev Soc Med 30 (1976) 225-230.

8. Gray TJB, Butterworth KR, Gaunt IF, Grasso P, Gongolli SD. Short term toxicity study of di(ethylhexyl)phtalate in rats. Food Cosmet Toxicol 15 (1977) $389-399$.

9. International Agency for Research on Cancer. Cadmium, nickel, some epoxides, miscellaneous industrial chemicals and general considerations on volatile anaesthetics. Lyon 1976. (Monographs on the evaluation of the carcinogenic risk of chemicals to humans, volume 11).

10. International Agency for Research on Cancer. Some monomers, plastics and synthetic elastomers, and acrolein. Lyon 1979. (Monographs on the evaluation of the carcinogenic risk of chemicals to humans, volume 19).

11. International Agency for Research on Cancer. Some industrial chemicals and dyestuffs. Lyon 1982. (Monographs on the evaluation of the carcinogenic risk of chemicals to humans, volume 29).

12. Marsch GM. Mortality among workers from a plastic producing plant: A matched case-control study nested in a retrospective cohort study. J Occup Med 25 (1983) 219-230.

13. McMichael AJ. Standardised mortality ratios and the "healthy worker effect": Scratching beneath the surface. J Occup Med 18 (1976) 165-168.

14. Pedersen E, Høgetvert AC, Andersen A. Cancer of respiratory organs among workers at a nickel refinery in Norway. Int J Cancer 12 (1970) 32-41.

15. Thomas TL, Decoufle P, Mour-Eroso R. Mortality among workers employed in petroleum refining and petrochemical plants. J Occup Med 22 (1980) 97-103.

16. Waxweiler RV, Alexander V, Leffingwell SS, Haring M, Lloyd W. Mortality from brain tumor and other causes in a cohort of petrochemical workers. J Natl Cancer Inst 70 (1983) $75-81$.

17. World Health Organization. Manual of the international statistical classification of diseases, injuries, and causes of death: Sixth revision of the international lists of diseases and causes of death adopted - 1948. Volumes 1 and 2. Geneva 1949.

18. World Health Organization. Manual of the international statistical classification of diseases, injuries, and causes of death. Seventh revision. Volume 1. Geneva 1957.

19. World Health Organization. Manual of the international statistical classification of diseases, injuries, and causes of death. Eighth revision. Volume 1. Geneva 1967.

20. World Health Organization. Manual of the international statistical classification of diseases, injuries, and causes of death. Ninth revision. Volume 1. Geneva 1975.

Received for publication: 29 November 1985 